\title{
Design of Control System for the Intelligent Auxiliary Medicine Taking Device
}

\author{
Xiong Wang ${ }^{1, a^{*}}$ and Xiaole Liu ${ }^{1, b}$ \\ ${ }^{1}$ Yulin University, Yulin, Shanxi, 719000, P.R. China \\ a12296832@qq.com, ${ }^{b} 1049605582 @ q q . c o m$
}

Keywords: Control system; Automatic medicine delivery; Fix-quantity water supply; Information transmission

\begin{abstract}
Aiming at the problems of the elderly patients who suffer from the medication process, such as forget to take the medicine, inadequate drug absorption, and the inconvenience of family members monitor, the control system of the intelligent auxiliary medicine taking device is designed in this paper. The hardware system is designed with the automatic reminding and medicine delivery module, constant-temperature and fix-quantity water supply module, and the information transmission module. The control flow of the system is analyzed. The experiment shows that the intelligent auxiliary medicine taking device can work properly and accomplish the task, which verifies the feasibility of the control system.
\end{abstract}

\section{Introduction}

Global aging problem is very severe. According to statistics of China's Statistical Bureau, the total population in China was more than 1.36 billions in 2015, including 0.21 billions of aged population. With the increase of aged population, aged diseases grow accordingly, resulting in the increasing drug taking of the aged. One research report of Canada's Health Information Institute pointed out 2/3 of the aged population in Canada take at least five prescription medicines. In China, the medicine taking frequency of the elderly reaches as high as $77.6 \%$. Each old man takes 3.16 medicines in average and $15.2 \%$ of the aged population has to take at least 5 medicines [1,2].

Missing, error taking or repeated taking of one or more medicines are common in the elderly, which will cause serious consequences. Moreover, improper water temperature and amount also will influence absorption of medicines. Poor care of the elderly exists in both homes and medical care places. Existing researches on auxiliary medicine-taking device only focused on automatic reminding, but none have explored automatic medicine delivery and constant-temperature and fix-quantity water supply, thus failing to protect correct taking of medicines and ensure absorption rate of medicines. To address these problems, this paper designed a control system for the available laboratory medicine delivery device $[3,4]$.

\section{Design Requirements of the Control System}

The control system shall be designed expandable and revisable according to the system functions. Meanwhile, it shall protect modularization of the control system, which is conducive for the control system design, task splitting and fast troubleshooting[5,6,7].

Intelligent auxiliary medicine taking device requires the control system to remind patients to take medicines accurately on time. To ensure full absorption of medicines, it shall offer patients appropriate water temperature and quantity and inform family members of the patient after taking medicines, thus enabling to monitoring the patients. Specific requirements are:

(1) Delivery accurate medicines automatically on time and give voice prompt;

(2) Be able to set times and time of medicine taking;

(3) Provide $200-250 \mathrm{ml} 40-50^{\circ} \mathrm{C}$ water to ensure medicine absorption to the maximum extent;

(4) Send SMS to family members after every medicine taking 


\section{Overall Design}

Considering simplification and convenience, a control system with two controllers (Fig. 1) was designed to meet requirements of intelligent auxiliary medicine taking device, which could realize module-based control of the whole control system[8,9,10].

Two master controllers used STC89C52 series singlechip. Without adequate interfaces, two singlechips were chosen for controlling. The STC89C52 singlechip contains 40 I/O pins. Some pins connect to power circuit, clock circuit and reset circuit, forming the minimum system for normal operation of the singlechip. Other I/O pins connect to rest circuit modules.

The controller I is mainly responsible for automatic reminding and medicine delivery, while the controller II is mainly responsible for controlling the constant-temperature and fix-quantity water supply module and the information transmission module. The controller II triggers module control by testing the low level of the controller I.

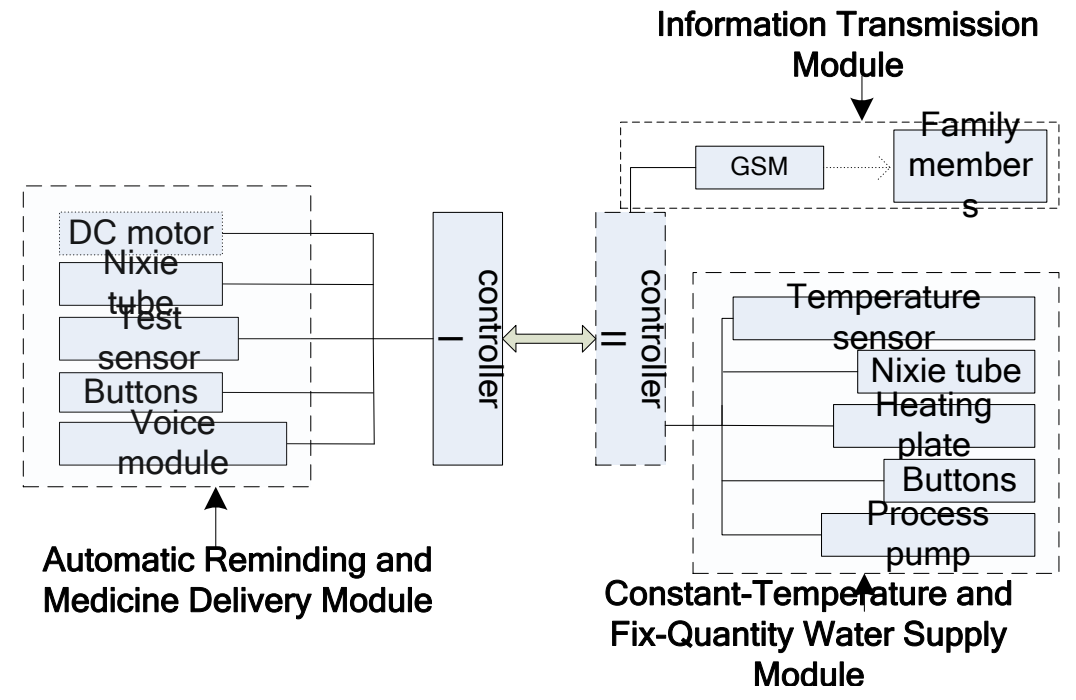

Figure 1. Control System

Automatic Reminding and Medicine Delivery Module Design. The automatic reminding and medicine delivery module is mainly for reminding patients to take medicines and delivery correct medicines to patients. Exiting medicine delivery device in laboratory ensures accuracy of medicine delivery by motor driven turntable. Start time, times and interval to take medicines are set in the controller I by buttons. Each button is connected to one indicating circuit to test whether the button circuit operates normal. The I/O interface of singlechip drives the Nixie tube directly to display settings. The system uses 4-bit 8 segments Nixie tube for LED dynamic display. The controller I reminds patients to take medicines through the voice module and delivers medicines by driving the DC motor to rotate the turntable. The system uses the L9110 chip to drive the motor circuit. The position test circuit is mainly responsible to test positions of the turntable. In the control system, a touch switch is used as the test sensor whose normally open is connected with the controller. When the medicine storage turntable is at the groove, the touch switch is triggered by the medicine storage turntable and closes from normally open. The controller make judgment according to the switch state to stop the motor and ensure accurate delivery of medicines. The voice alarm circuit is mainly for give voice prompt by connecting with the external SYN6288 voice synthesis module. At the set time, the voice alarm circuit will remind users to take medicines on time.

Constant-Temperature and Fix-Quantity Water Supply and Information Transmission Module Design. The constant-temperature and fix-quantity water supply module is mainly to provide patients water with set temperature and quantity, aiming to increase absorption rate of medicines. The constant-temperature module is mainly composed of a temperature sensor, a heating plate and nixie tubes. Nixie tubes also use 4-bit 8 segment ones and adopt LED dynamic display. The temperature sensor chooses stainless steel sealed waterproof DS18B20 temperature probe which requires no 
external components and has a special unibus interface. It is characteristic of wide temperature range and simple control. The heating device is a $2000 \mathrm{~W}$ heating plate. Fix-quantity water supply is mainly accomplished by a process pump. The process pump chooses the Pump series mini membrane pump which has small volume, long service life, free maintenance, PWM optional and controllable wide flow range. The information transmission module uses GSM module and the Germany Siemens TC35 module. It has stable performance and the interface supports serial R232 and TTL adaptive singlechip, which are convenient for controlling.

\section{Control Realization}

Overall Control. The control flow of the intelligent auxiliary medicine taking device is shown in Fig. 2. Family members of patients shall set times and time and put medicines properly in advance. At the time for taking medicines, the voice module will remind the patient to "take medicine". The patient shall press the picking button and the system will enter into automatic medicine delivery module, constant-temperature and fix-quantity water supply module and information transmission module. After that, it will turn to the next timing program and wait for the next time of taking medicine. This process will repeat until all medicines of one day have taken.

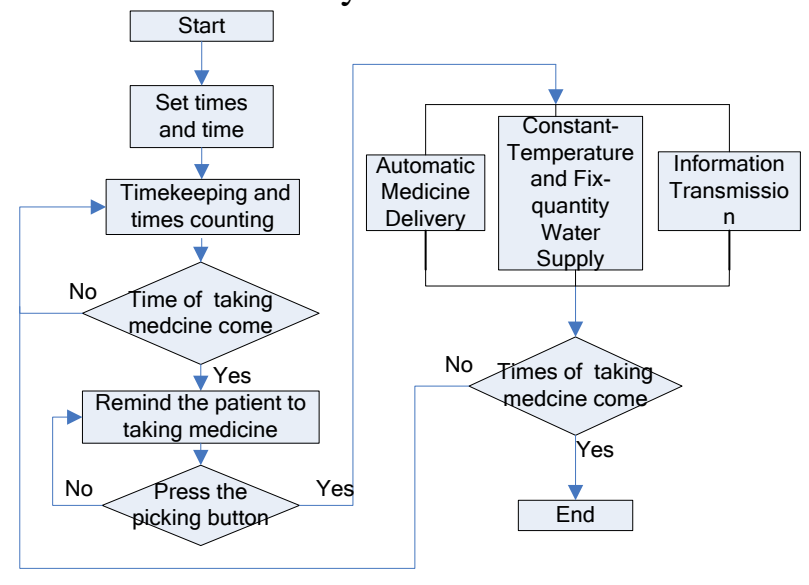

Figure 2. Overall Control

Automatic Medicine Delivery Control. The automatic medicine delivery control is presented in Fig. 3. After receiving command of taking medicine, the controller I drives the motor until the position sensor perceives that the turntable is at the correct position. This is one automatic medicine delivery.

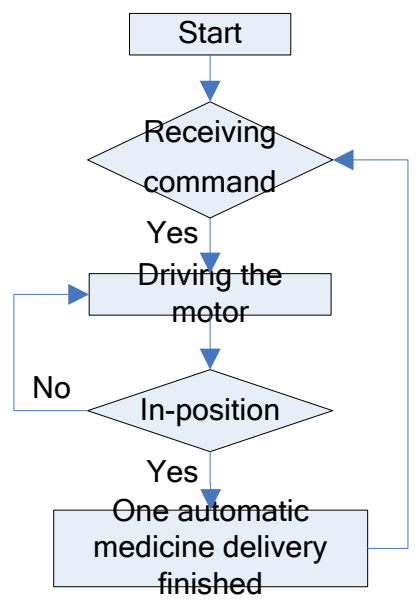

Figure 3. Automatic Medicine Delivery Control

Constant-Temperature and Fix-quantity Water Supply and Information Transmission Control. The constant-temperature and fix-quantity water supply and information transmission 
flowchart is exhibited in Fig. 4. Water temperature is set and the water-temperature sensor detects the water temperature. If it is lower than $42^{\circ} \mathrm{C}$, start the heating plate and control it through a relay. If it is higher than $48^{\circ} \mathrm{C}$, stop heating. This controls water temperature constantly between $40^{\circ} \mathrm{C}-50^{\circ} \mathrm{C}$.

After the intelligent auxiliary medicine taking system receives the button information, the controller II drives the water pump and water flow is controlled by the flow detector until $250 \mathrm{ml}$ water is gained.

Similarly, after the intelligent auxiliary medicine taking system receives the button information, the patients have to take medicines. At this moment, it will send SMS to cell phone of family members through the GSM module.

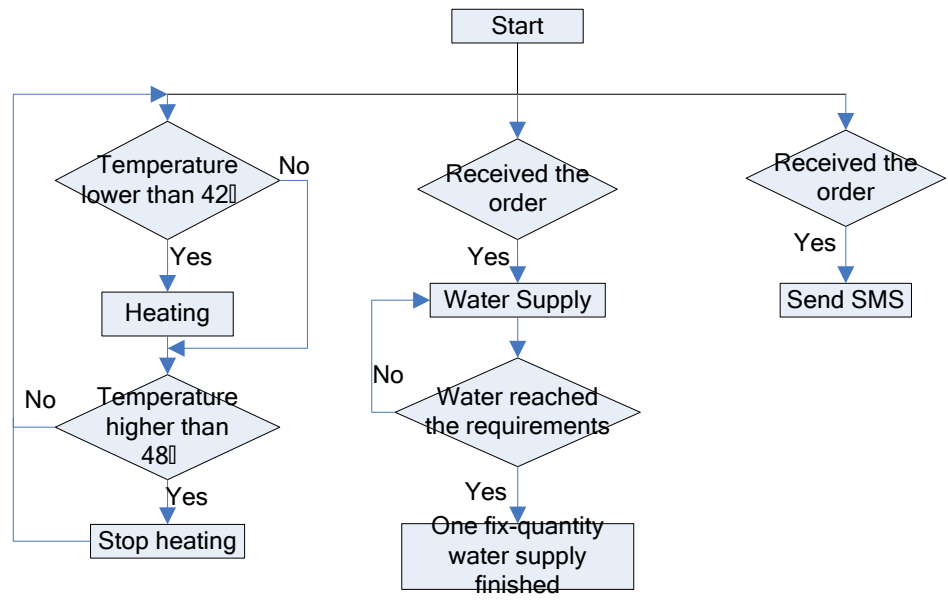

Figure 4. Constant-Temperature and Fix-quantity Water Supply and Information Transmission Control.

\section{Experimental Verification}

According to the control flow, $\mathrm{C}$ language is used for programming and experimental verification is conducted.

The intelligent auxiliary medicine taking device is shown in Fig. 5. The medicine box is used for keep medicines. The medicine storage turntable is used to put drugs for one day, starting from the 1\#. The water tank is for storing water. The control panel is mainly composed a constant-temperature control panel and a medicine delivery panel.

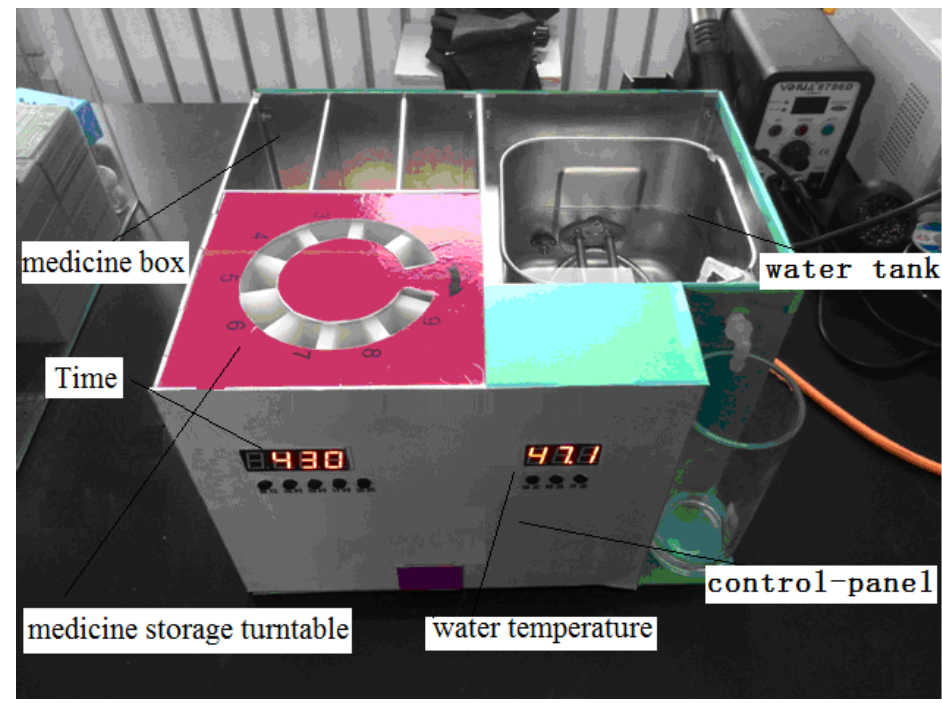

Figure 5. Intelligent Auxiliary Medicine Taking Device 
After times and time for taking medicine are set, the first timing program started. Next, the nixie tube blinked and reminded the patient to take medicines at the end of timing. At the same time, the voice module speaked "Please take medicines" repeatedly. The patient pressed the picking button, so the medicine storage turntable rotated to the outlet through internal channels and the system offered fixed quantity of water $(250 \mathrm{ml})$. Meanwhile, the system sent SMS to cell phone of family members.

The experiment shows that the intelligent auxiliary medicine taking device can accomplish the task.

\section{Summary}

(1) In this paper, a control system with two controllers is used to separate the control system for the intelligent auxiliary medicine taking device into several modules. This simplifies the system design and is convenient for problem recognition as well as system maintenance.

(2) The experiment has confirmed that the control system can operate normally. The system design is convenient to be used extensively in the intelligent auxiliary medicine taking device for its simple operation and low cost.

(3) The control system has positive significance to cope with current aging situation and safeguarding lives of the elderly.

\section{Acknowledgements}

This work was financially supported by the university-industry cooperation projects of Yulin science and technology Bureau (2014cxy-08-02).

\section{References}

[1] Information on http://health.zjol.com.cn.

[2] H. Liu and W.H. SHI: Chinese Journal of Disease Control \& Prevention, Vol. 20 (2016) No.2, p. 121-124(In Chinese).

[3] B. Liu, Y.H. Wen and X.F. Zhou: Advances in Difference Equations, (2015) No.1, p.1-10.

[4] N.K. Sura and S. Suryanarayan: Journal of Aircraft, Vol.46 (2009), No.2, p.505-509.

[5] M.J. Yu, F.P. Cao, T.Q. Xu and X.Y. Qiu: Advanced Materials Research, Vol.1673 (2012) No.479, p.1433-1437.

[6] Q. Zhang, J.J. Zhang, J. He, Y.F. Li and X.R. Qin: Advanced Materials Research, Vol.1037 (2010) No.139, p.2440-2445.

[7] P. Thota, B. Krauskopf and M. Lowenberg: Nonlinear Dynamics, Vol.70 (2012) No.2, p.1675-1688.

[8] L.J. He and Y.C. Zhou: Applied Mechanics and Materials, Vol.2525 (2013) No.344, p.61-65.

[9] V.P. Zhuravlev and D.M. Klimov: Doklady Physics, Vol.54 (2009) No.10, p.475-478.

[10]F. Feng, H. Nie, M. Zhang and Y. Peng: Journal of Vibroengineering, Vol.16 (2014) No.1, p.275-291. 